\title{
Unusual increase of psittacosis in southern Sweden linked to wild bird exposure, January to April 2013
}

\author{
M Rehn (moa.rehn@smi.se)1,2, H Ringberg ${ }^{3}$, A Runehagen 4 , B Herrmann5, B Olsen 6 , A C Petersson ${ }^{7}$, M Hjertqvist ${ }^{1}$, \\ S Kühlmann-Berenzon ${ }^{1}$, A Wallensten ${ }^{1}$ \\ 1. Swedish Institute for Communicable Disease Control, Solna, Sweden \\ 2. European Programme for Intervention Epidemiology Training (EPIET), European Centre for Disease Prevention and Control \\ (ECDC), Stockholm, Sweden \\ 3. Department of Communicable Disease Control, Skåne county, Malmö, Sweden \\ 4. Department of Communicable Disease Control, Kronoberg county, Växjö, Sweden \\ 5. Department of Medical Sciences, Clinical Bacteriology, Uppsala University, Uppsala, Sweden \\ 6. Department of Medical Sciences, Infectious Diseases, Uppsala University, Uppsala, Sweden \\ 7. Clinical Microbiology, University and regional Laboratory, Lund, Sweden
}

Rehn M, Ringberg H, Runehagen A, Herrmann B, Olsen B, Petersson AC, Hjertqvist M, Kühlmann-Berenzon S, Wallensten A. Unusual increase of psittacosis in southern Sweden linked to wild bird exposure, January to April 2013. Euro Surveill. 2013;18(19):pii=20478. Available online: http://www.eurosurveillance.org/ ViewArticle.aspx?Articleld $=2047$

Free-living wild birds worldwide act as reservoir for Chlamydia psittaci, but the risk of transmission to humans through contact with wild birds has not been widely documented. From 12 January to April 9 2013, a total of 25 cases of psittacosis were detected in southern Sweden, about a threefold increase compared with the mean of the previous 10 years. A matched casecontrol study investigating both domestic and wild bird exposure showed that cases were more likely than controls to have cleaned wild bird feeders or been exposed to wild bird droppings in other ways (OR: 10.1; 95\% Cl: 2.1-47.9). We recommend precautionary measures such as wetting bird feeders before cleaning them, to reduce the risk of transmission of $C$. psittaci when in contact with bird droppings. Furthermore, $C$. psittaci should be considered for inclusion in laboratory diagnostic routines when analysing samples from patients with atypical pneumonia, since our findings suggest that psittacosis is underdiagnosed.

\section{Introduction}

From 12 January to 9 April 2013, 25 cases of psittacosis were detected in southern Sweden. Only one case had been reported during the preceding months in 2012. Psittacosis has been a notifiable disease in Sweden since 1969. A mean of seven cases (SD: 3.3) per year have been reported in Sweden over the last 10 years [1]. The cases were found in the counties of Skåne, Kronoberg, Kalmar and Östergötland, in the south of the country. Of the 25 cases, 23 were in Skåne and Kronoberg. In order to identify the source of the outbreak, county medical officers and the Swedish Institute for Communicable Disease Control (SMI) conducted an outbreak investigation.

Free-living wild birds worldwide act as reservoirs for Chlamydia psittaci. The bacterium mainly infects birds but can also be transmitted to mammals. In addition to humans, C. psittaci has also been found in cattle, sheep and rodents [2] In humans, the disease is termed psittacosis or parrot disease, as it was first recognised in 1929, when about 800 cases of pneumonia were reported around Europe in an outbreak caused by exposure to C. psittaci-infected parrots imported from South America [3]. Although domestic birds are the most common source for infection in humans [4], wild bird species have also been shown to be a source of $C$. psittaci, leading to infection in humans, spanning from single cases to outbreaks. In the 1930s, fulmars (Fulmarus glacialis) that were probably infected with C. psittaci from dead parrots thrown overboard during transport from South America to Europe were hunted for food; this resulted in large psittacosis outbreaks in humans on the Faroe Islands and in Iceland [3]. In recent years, outbreaks of psittacosis in Australia have been linked to lawn mowing in gardens polluted by wild bird droppings $[5,6]$. However, the risk of transmission of C. psittaci through contact with wild birds has not been widely documented.

The preferred name for the disease in birds is avian chlamydiosis, although the names ornithosis and psittacosis are commonly used. The epizootiology in wild birds has not been studied extensively, but to date, $C$. psittaci has been detected in around 460 bird species within 30 orders [7]. Passerine birds (including species most frequently visiting bird feeders in gardens) have formerly not been considered to play an important role as major hosts, but there have been reports that, in the Passeriformes order, many species are carriers of the bacterium $[8,9]$. A wide prevalence variation is seen in studies of $C$. psittaci in wild birds $[8,10,11]$ and can partly be explained by different diagnostic techniques and even methodological problems. Swedish studies based on DNA detection have found prevalence rates 
between $1 \%$ and $3 \%$ in falcons, eagles [11], wetland birds [10] and passerines [8].

C. psittaci is excreted by infected birds in their faeces and other body fluids, and the microorganism can remain infectious for several months outside the host $[12,13]$. Birds get infected through inhaling or ingesting the bacteria, and the infection may persist for months, although the birds may only excrete the bacteria intermittently. Stress factors such as migration, crowding, weather changes and breeding can activate the excretion. Overt disease is unusual in wild birds [13].

Humans become infected by inhaling the bacteria through contact with contaminated bird secretions, dried-out droppings or dust from feathers [12]. Human-to-human transmission has been suggested and thought to be rare $[12,14]$, but it has not been extensively documented. The incubation period is one to four weeks, and clinical symptoms are compatible with influenza-like illness and include fever, rigors, sweats, headache, myalgia and mild cough $[15,16]$. Most infected people do not show any symptoms or only experience a mild influenza-like illness. However, some develop systemic illness with severe atypical pneumonia, which can be serious and sometimes fatal. The infection can be treated with antibiotics with intracellular action.

\section{Methods}

The 23 cases in Skåne and Kronoberg were investigated further by the county medical officers. The investigation identified a cluster of eight cases (four probable and four confirmed), all linked to one index patient treated in a hospital and thus nosocomial human-tohuman transmission was suspected. Due to the rarity of this event, the human-to-human transmission cluster will be described in a separate publication.

A confirmed case was defined as a person with a clinical diagnosis of psittacosis and laboratory confirmation either by detection of $C$. psittaci in respiratory secretions by polymerase chain reaction (PCR) or by an antibody (IgG or IgM) titre of 256 or greater.

A probable case was defined as a person with a clinical diagnosis of psittacosis with an IgG titre between 64 and 256.

\section{Case-control study}

We conducted a case-control study among the 23 cases in Skåne and Kronoberg to investigate potential risks of contracting psittacosis that were associated with different bird exposures, in particular wild bird exposures. All 23 cases (19 confirmed and 4 probable), with symptom onset between 31 December and 27 March and notified before 9 April, were invited to take part in the study. Eight cases (four probable and four confirmed) from the human-to-human transmission cluster were excluded. Consequently, 15 confirmed cases were included in the case-control study.
Six controls per case were selected from the population registry (Infotorg) and were matched to the cases by postal code, sex and age ( \pm 5 years). Matching was performed partly to facilitate control selection but also to adjust for disparity in age and sex distribution of cases and differences in behaviour related to living in or outside urban areas. We asked cases and controls to fill out a web-based or paper questionnaire on the following: exposure to domestic and wild birds; history of visits to pet shops; exposure to rodents; and habits of outdoor activities.

The exposure period for cases was defined as one to four weeks before symptom onset. For controls, the exposure period was defined as the calendar months corresponding to the calendar months of the matched case's exposure period.

A variable for exposure to wild birds (yes/no) was defined as either feeding wild birds or having other contact with wild birds that was not feeding. Other contact included activities such as cleaning bird feeders or other areas covered with bird droppings and contact with dead birds.

All exposures to domestic birds were grouped into one single variable. Domestic bird exposure included history of visiting a pet shop, contact with domestic birds at home or contact with domestic birds outside of the home.

Contact with rodents was included as a question as C. psittaci has been identified in rodents.

All statistical analyses consisted of conditional logistic regression from which odds ratios (OR) and $95 \% \mathrm{Cls}$ were obtained. We first performed univariate analysis to explore possible individual risk factors and obtain crude ORs. In the multivariable model, we included those exposures with a $p$ value $\leq 0.2$ in the univariate analysis, as well as age and exposure to domestic birds. Age was included to control for residual confounding since the age difference between controls that were matched to the same case could be up to 10 years. As exposure to domestic birds is known to be associated with psittacosis, it was included to correct for its potential effect on the other included associations. Statistical analysis was performed using Stata 12.

\section{Laboratory investigation}

C. psittaci was identified in respiratory samples by amplification of an 84 base pair (bp) fragment of the outer membrane protein A gene (ompA) according to Heddema et al. [17]. The assay was run as a duplex real-time PCR including screening for Legionella species and an internal amplification control. In order to determine the genotype of C. psittaci, all PCRpositive samples were further investigated by amplification and sequence analysis of a $560 \mathrm{bp}$ fragment of ompA covering variable domain I and II. IgG and 
Sporadic psittacosis cases in southern Sweden by week of symptom onset, reported between 12 January and 9 April 2013 (weeks 1-13) $(\mathrm{n}=17)^{\mathrm{a}}$

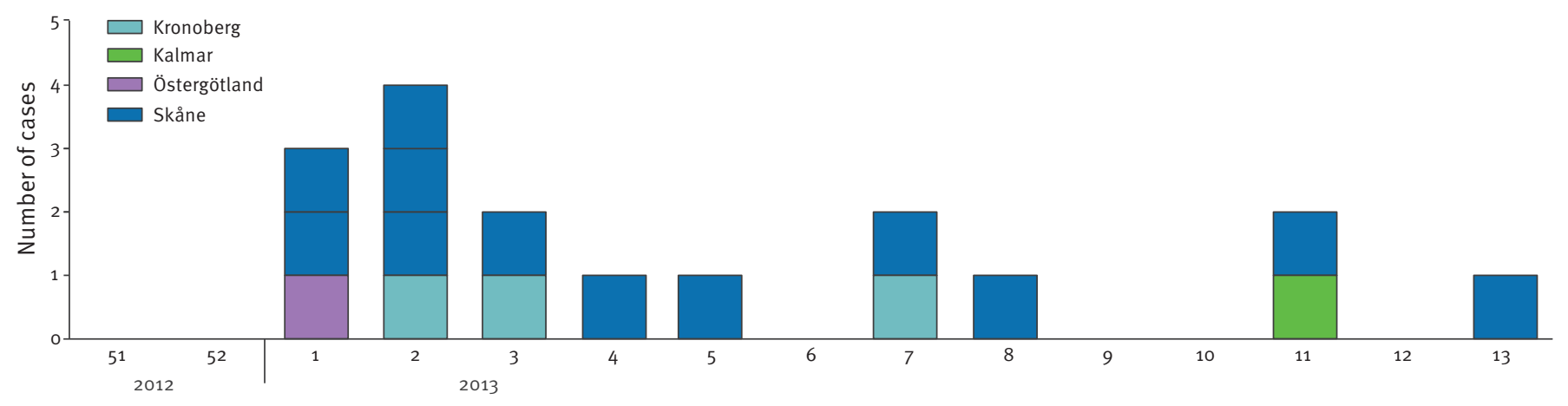

${ }^{a}$ Cases from the human-to-human transmission cluster $(n=8)$ are not shown.

IgM antibodies specific to C. psittaci were shown by microimmunofluorescence.

Two bird dropping samples from a parrot and a hen, kept by two cases respectively, were analysed for C. psittaci using the MagAttract Viral RNA M48 extraction kit (Qiagen, Hilden, Germany) and real-time PCR detection of the $23 \mathrm{~S}$ gene, as previously described [18].

No samples were collected from cases' bird feeders.

\section{Results}

The cases' symptoms started between 31 December 2012 and 27 March 2013 (weeks 1-13) (Figure 1). The cases were found in the counties of Skåne (12 confirmed cases), Kronoberg (7 confirmed cases, 4 probable cases), Kalmar (1 confirmed case) and Östergötland (1 confirmed case) (Figure 2).Among the 23 cases in Skåne and Kronoberg, 16 were men. The median age was 66 years (range: 37-88) for men and 47 years (range: $34-72)$ for women. The majority of cases $(n=21)$ had verified pneumonia. Two cases were diagnosed after recovery, thus no clinical verification was performed. A total of 19 cases were hospitalised: one case had a fatal outcome.

\section{Case-control study results}

All 15 sporadic cases and 51 of the 90 controls responded to the questionnaire (response rates of $100 \%$ and $57 \%$, respectively).

The crude ORs for examined exposures and adjusted ORs for exposures included in the final model are presented in the Table. The univariate analysis identified that there was no statistically significant association between psittacosis and any type of exposure to wild birds (OR: 7.8; 95\% Cl: 1.0-64.0). When looking at more specific types of exposures to wild birds, a stronger association was identified between psittacosis and contact with wild birds other than feeding (OR: 10.1; $95 \% \mathrm{Cl}: 2.1-47.9)$, whereas the association with feeding wild birds was weaker and not statistically significant (OR: 2.6; 95\% Cl: 0.6-11.0). Of the 15 cases, 10 had been exposed to wild birds in other ways than feeding.

The final conditional logistic model included any contact with domestic birds, feeding wild birds, contact with wild birds other than feeding and age. When adjusting for the other exposures in the model, contact with wild birds other than feeding was the only exposure that remained statistically associated with psittacosis (adjusted OR: 26.4; $95 \% \mathrm{Cl}: 2.0-348.6$ ).

\section{Laboratory findings}

All 15 patient samples that were analysed by PCR were positive. Genotyping by sequence analysis of an approximately $500 \mathrm{bp}$ fragment of the ompA gene was attempted for 12 samples and was successful in four. The obtained sequences were identical and clustered within genotype $A$. These patient samples originated from different parts of Skåne and Kronoberg. Eight cases were diagnosed using serology.

C. psittaci could not be detected in bird droppings from the parrot and the hen.

\section{Control measures}

Due to the increase in the number of psittacosis cases this winter in Sweden, county medical officers and the Swedish Institute for Communicable Disease Control (SMI) notified the public and healthcare services on 20 March 2013 about potential risks associated with handling bird feeders. The purpose was to increase awareness about the illness and about preventive measures. On 22 March, the situation was summarised in a ProMED article [19], resulting in some international correspondence, (personal communication Ander Wallensten) but no reports of an increased number of human cases in 


\section{FIGURE 2}

Distribution of psittacosis cases in southern Sweden, reported between 12 January and 9 April $2013(\mathrm{n}=17)^{\mathrm{a}}$

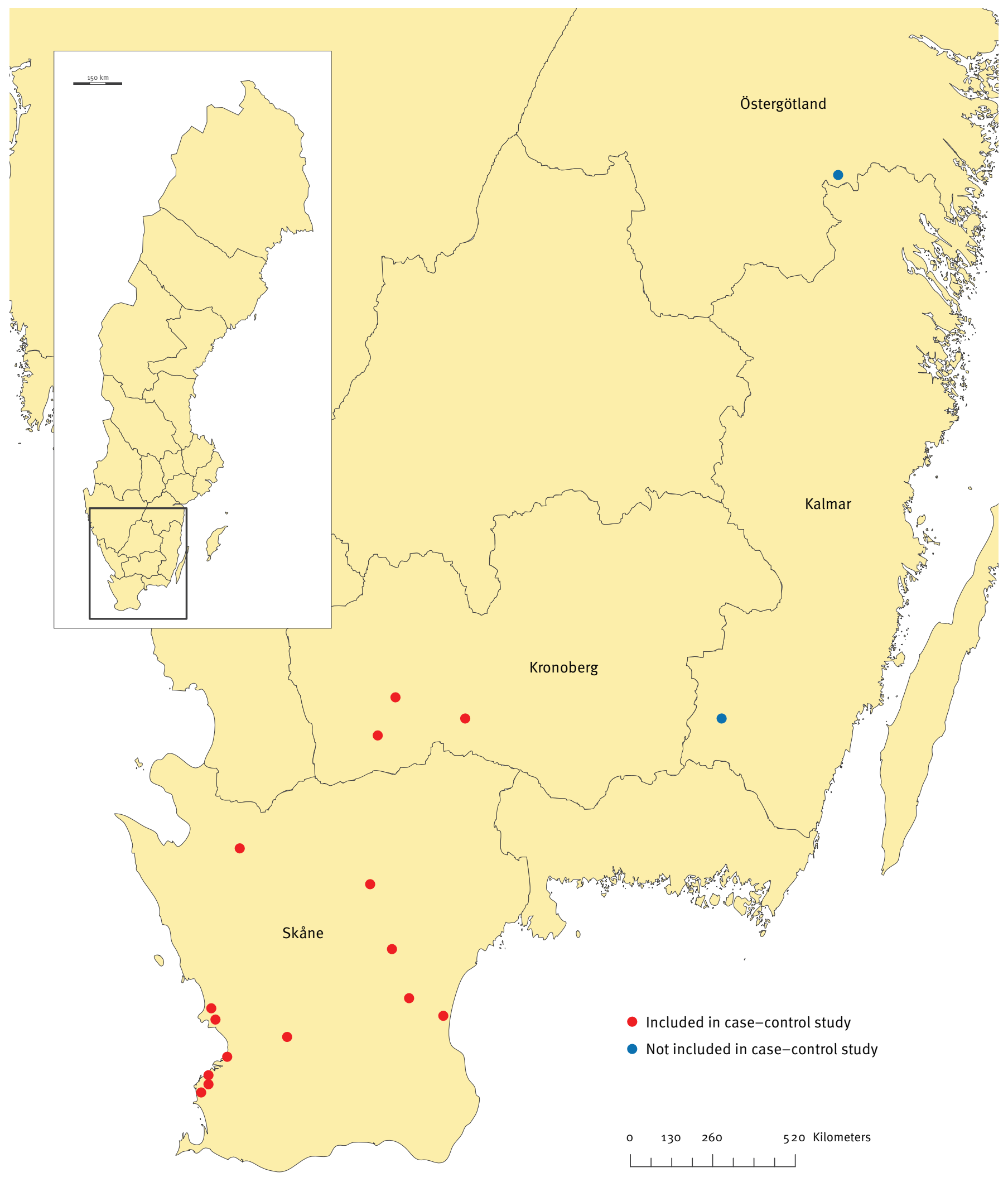

${ }^{a}$ Cases from the human-to-human transmission cluster $(\mathrm{n}=8)$ are not shown. 
Potential risk factors associated with psittacosis among psittacosis cases $(n=15)$ and matched controls $(n=51)$ in southern Sweden, December 2012-March 2013

\begin{tabular}{|c|c|c|c|c|c|c|}
\hline \multirow[b]{2}{*}{ Potential risk factor } & \multicolumn{2}{|c|}{ Exposed } & \multicolumn{2}{|c|}{ Crude } & \multicolumn{2}{|c|}{ Adjusted } \\
\hline & $\begin{array}{c}\text { Number of } \\
\text { cases }\end{array}$ & $\begin{array}{c}\text { Number of } \\
\text { controls }\end{array}$ & $\mathrm{OR}^{\mathrm{a}}(95 \% \mathrm{Cl})$ & $P$ value & $\mathrm{OR}^{\mathrm{a}, \mathrm{b}}(95 \% \mathrm{Cl})$ & P value \\
\hline $\mathrm{Age}^{\mathrm{c}}$ & - & - & $0.7(0.4-1.2)$ & 0.200 & $0.6(0.4-1.2)$ & 0.145 \\
\hline Any contact with domestic birds & 4 & 7 & $2.2(0.5-9.2)$ & 0.296 & $7.0(0.5-95.6)$ & 0.147 \\
\hline Visit to shop with caged birds & 2 & 2 & $3.4(0.5-24.5)$ & 0.229 & - & - \\
\hline Contact with domestic birds at home & 3 & 4 & $2.8(0.5-14.8)$ & 0.281 & - & - \\
\hline Any contact with wild birds & 12 & 25 & $7.8(1.0-64.0)$ & 0.054 & - & - \\
\hline Feeding wild birds & 10 & 25 & $2.6(0.6-11.0)$ & 0.190 & $0.6(0.1-4.9)$ & 0.625 \\
\hline Contact with wild birds other than feeding & 10 & 10 & $10.1(2.1-47.9)$ & 0.004 & $26.4(2.0-348.6)$ & 0.013 \\
\hline Contact with rodents & 6 & 14 & $2.1(0.5-8.3)$ & 0.313 & - & - \\
\hline Outdoor activities & 12 & 39 & $1.1(0.2-4.8)$ & 0.920 & - & - \\
\hline
\end{tabular}

$\mathrm{Cl}$ : confidence interval; OR: odds ratio.

a Missing values excluded.

Adjusted for all the other exposures in the model. Conditional logistic regression model included any contact with domestic birds, feeding wild birds, contact with wild birds other than feeding and age.

Age was included in the multivariable model to control for residual confounding since the age difference between controls that were matched to the same case could be up to 10 years.

other countries, apart from a ProMED report on 5 April describing a sixfold increase in psittacosis incidence over the past 10 years in Saint Petersburg, Russia, according to the Department of the Federal Service on Supervision of Protection of Consumer Rights and Human Well-Being in Saint Petersburg [20].

The Swedish National Veterinary Institute (SVA) did not receive any reports of increased mortality among wild birds during this winter [21].

To date, one additional case of psittacosis has been reported from Skåne, on 10 April.

\section{Discussion}

It was apparent after the initial investigation of cases conducted by the county medical officers that the only bird exposure among most cases was exposure to wild birds, mainly by tending bird feeders in their gardens. The results of our study showed that cases were more likely than controls to have been cleaning bird feeders or exposed to bird droppings in other ways. However, assuming that wild bird feeding, handling of bird feeders and exposure to droppings and dead birds have been relatively constant activities over the years, we still need an explanation as to why more people have been diagnosed with psittacosis this year.

One explanation could be that weather conditions were unfavourable for wild birds this winter, which may have induced increased excretion of the bacteria in C. psittaci-carrying birds and thereby caused abnormal contamination of bird feeders. This year's national bird count at bird feeders noted a general decline in numbers for most species, indicating that many birds may have succumbed this winter [22]. The Swedish Meteorological and Hydrological Institute summarised the winter as having been relatively usual, but it had prolonged periods of low temperatures and fast weather changes [23-25]. Feeding wild birds may enhance the risk of local epizootics as the birds congregate in potentially contaminated feeders.

There is no surveillance system in place for avian chlamydiosis in wild birds in Sweden although unusual findings of sick or dead birds are usually reported by the public to the Swedish National Veterinary Institute. There was no increase in the number of such reports this winter [21], but this does not rule out an increased infection prevalence or increased excretion in the wild bird population, as birds rarely become overtly ill. It may also be difficult to notice such an increase in sick and immobilised birds, as they become easy prey, e.g. for sparrow hawks, pygmy owls and cats.

A second explanation could be that a C. psittaci strain more pathogenic or transmissible in humans circulated in the wild bird population this year. That there are differences in the virulence of a strain for different hosts has been long known. In the Faroe Islands' outbreak of the 1930s, the strain was found to be of low pathogenicity to the fulmars, while it caused severe disease 
in the humans handling them [3]. Partial genotyping of ompA showed that four of the cases in this current outbreak were caused by C. psittaci ompA type A, suggesting that they could have been infected from the same source. Further genotyping including complete sequence analysis of ompA combined with multi-locus sequence typing (MLST) [26] may provide insight into whether a common source explains the current outbreak. However, currently MLST requires access to isolates of $C$. psittaci, which is difficult to obtain in clinical routine diagnostics and requires expertise and equipment of biosafety level 3. Type $\mathrm{A}$ of ompA - the type causing the majority of reported human psittacosis cases [27] - is primarily associated with psittacine birds, but has also been found in other bird species including tits [8], fulmars [28] and poultry [29]. Although C. psittaci genotyping has been predominantly determined by ompA analysis, recent investigations show that type A strains with identical ompA genes can differ considerably in virulence and that the virulence is confined to a few single nucleotide polymorphisms [30]. To rule out the possibility of a more pathogenic strain occurring in this outbreak, further genome analysis is needed.

The clinical picture of psittacosis may be similar to disease caused by other agents such as Mycoplasma pneumoniae, Chlamydia pneumoniae and Legionella species [31] as well as to that of respiratory illness caused by influenza, which was also circulating at the time [32]. However, a C. psittaci-positive PCR result in combination with relevant symptoms is, in our opinion, robust evidence that the infections were caused by C. psittaci, especially since the other agents were in most cases excluded by testing.

One likely explanation as to why cases mainly occurred in two counties in southern Sweden is that different diagnostic routines are in place in the clinical laboratories. Since 2005, the laboratory that diagnosed most of the cases in this outbreak has routinely tested for C. psittaci when a sample from a patient with atypical pneumonia is submitted for Legionella analysis. This is not the case in most other Swedish laboratories. Therefore it is likely that cases in other counties may have been missed. A partial review of four cases of atypical pneumonia in Kronoberg during this winter showed that two had not been tested for Legionella or C. psittaci, even though they tested negative for $M$. pneumoniae. Retesting of these undiagnosed cases revealed two additional suspected psittacosis cases, thus supporting the theory that cases may have been missed. This is an important observation, which indicates that psittacosis is an under-diagnosed disease and should be considered more often in cases of atypical pneumonia. Apart from this explanation, it is difficult to understand why cases occurred only in southern Sweden. The bird species most often visiting bird feeders in gardens in the southern part of Sweden (e.g. great tit, tree Sparrow, blue tit, green finch, bullfinch) [22] can be found in almost all parts of Sweden.
These species are relatively short-lived and migrate only within short distances during winter, depending on access to food.

Regardless of the small size of the study, a significant association between psittacosis and exposure to wild birds was shown. However, the risk may have been underestimated, as it could be assumed that controls who kept bird feeders in their gardens were more likely to have responded to the questionnaire, leading to a bias towards bird feeders among the controls. Almost half of the controls in this study had fed birds with bird feeders in their garden during December to March. Cases and controls often lived in small towns or in the country side, where bird feeding might be more frequent than in cities. Even if the population studied may not be representative of the Swedish population in general, this high proportion indicates that wild bird feeding is common in non-urban parts of southern Sweden.

The risk for psittacosis when exposed to wild birds is difficult to assess. Large outbreaks with $20 \%$ mortality were seen on the Faroe Islands in the $1930 \mathrm{~s}$ [3], whereas contemporary studies found no cases of psittacosis among people exposed to birds with a high prevalence (10\%) of infection [28]. Additionally, another study could not detect antibodies to C. psittaci among 65 bird ringers, a group with close exposure to a variety of birds, mainly passerines [8]. In general, the risk of human infection from contact with wild birds is likely to be low [33]. However, it can be expected to be higher if exposed to birds carrying C. psittaci that are suffering from stress or sickness leading to increased excretion of the bacteria.

\section{Public health implications}

This study shows that there is an association between exposure to wild birds through handling wild bird feeders and bird droppings during winter and psittacosis. Bird feeding alone, however, was not associated with disease. The actual risk is likely to vary geographically and over time due to epizootics in the wild bird population that may be aggravated by harsh weather conditions.

Wild bird feeding is a common and appreciated pastime in Sweden and should not be discouraged based on the results of this study. However, people feeding birds should be informed of the risk of handling bird droppings and how to minimise the risk, for example, by using safe practices when cleaning bird feeders and using bird feeders constructed to limit birds from defecating on the feeder. The Swedish Institute for Communicable Disease Control has previously recommended wetting the areas covered with bird droppings before removing them, hand washing after contact with bird droppings and only cleaning bird feeders in wellventilated areas [34]. For people working in heavily contaminated and confined rooms or areas, respiratory air filters should be used. On the basis of the findings 
from this current investigation, we support these recommendations.

Finally, an important recommendation from this study is that $C$. psittaci should be considered as a potential causative agent of atypical pneumonia. Inclusion of the pathogen in laboratory diagnostic routines when analysing samples from patients with atypical pneumonia is likely to identify more cases, and should therefore be considered.

\section{Acknowledgements}

We thank Caroline Bröjer at the Swedish national Veterinary Institute for information regarding observations in the wild bird population, as well as Hans Fredlund at the Department for Communicable Disease Control in Örebro for information about serological diagnostics. We would also like to acknowledge the contribution of EPIET coordinator Marion Muehlen, in reviewing this manuscript.

\section{Authors' contributions}

Moa Rehn was responsible for conducting the case-control study, data analysis and drafted the manuscript together with Anders Wallensten, who had the overall responsibility for the study. All authors revised and approved the final report submitted. Arne Runehagen and Håkan Ringberg were responsible for investigation of cases. Björn Herrmann performed analysis on bird samples and contributed with his expertise in the field. Björn Olsen contributed with his expertise in the field. Ann-Cathrine Petersson performed the laboratory diagnostics and genotyping of human samples. Sharon Kühlmann-Berenzon supervised the statistical analysis. Marika Hjertqvist is responsible for the surveillance of psittacosis in Sweden.

\section{Conflict of interest}

None declared.

\section{References}

1. Smittskyddsinstitutet (SMI). Parrot fever. Solna: SMI. Updated 8 Apr 2013. [Accessed 16 Apr 2013]. Available from: http://www.smittskyddsinstitutet.se/in-english/statistics/ parrot-fever/

2. Andersen AA. Serotyping of Chlamydia psittaci isolates using serovar-specific monoclonal antibodies with the microimmunofluorescence test. J Clinical Microbiol. 1991;29(4):707-11.

3. Rasmussen-Ejde R. Ueber eine durch Sturmvögel übertragbare Lungenerkrankung auf den Färöern. [About a fulmar related transmission of lung disease in the Faroe Islands]. Zentralblatt für Bakteriologie, Parasitenkunde und Infektionskrankheiten, Erste Abteilung Originale. 1938;143:89-93. German.

4. Smith KA, Bradley KK, Stobierski MG, Tengelsen LA; National Association of State Public Health Veterinarians Psittacosis Compendium Committee. Compendium of measures to control Chlamydophila psittaci (formerly Chlamydia psittaci) infection among humans (psittacosis) and pet birds, 2005. J Am Vet Med Assoc. 2005;226(4):532-9.

5. Telfer BL, Moberley SA, Hort KP, Branley JM, Dwyer DE, Muscatello DJ, et al. Probable psittacosis outbreak linked to wild birds. Emerg Infect Dis. 2005;11(3):391-7. http://dx.doi.org/10.3201/eid1103.040601 PMid:15757553 PMCid:3298256

6. Williams J, Tallis G, Dalton C, Ng S, Beaton S, Catton M, et al. Community outbreak of psittacosis in a rural Australian town. Lancet. 1998;351(9117):1697-9.

http://dx.doi.org/10.1016/So140-6736(97)10444-5
7. Kaleta EF, Taday EM. Avian host range of Chlamydophila spp. based on isolation, antigen detection and serology. Avian Pathol. 2003;32(5):435-61.

8. Olsen B, Persson K, Broholm KA. PCR detection of Chlamydia psittaci in faecal samples from passerine birds in Sweden. Epidemiol Infect. 1998;121(2):481-4. http://dx.doi.org/10.1017/So950268898001320 PMid:9825803 PMCid:2809549

9. Simpson VR, Bevan R. Chlamydia psittaci infection in robins. Veterinary Rec. 1989;125(21):537. http://dx.doi.org/10.1136/vr.125.21.537-b

10. Blomqvist M, Christerson L, Waldenström J, Herrmann B, Olsen B. Chlamydia psittaci in Swedish wetland birds: a risk to zoonotic infection? Avian Dis. 2012;56(4):737-40. http://dx.doi.org/10.1637/10105-022812-ResNote.1 PMid:23397847

11. Blomqvist $M$, Christerson L, Waldenström J, Lindberg $P$, Helander B, Gunnarsson G, et al. Chlamydia psittaci in birds of prey, Sweden. Infect Ecol Epidemiol. 2012;2.

12. Compendium of measures to control Chlamydia psittaci infection among humans (psittacosis) and pet birds (avian chlamydiosis), 2000. Centers for Disease Control and Prevention. MMWR Recomm Rep. 2000;49(RR-8):3-17.

13. Thomas NJ, Hunter DB, Atkinson CT. Infectious diseases of wild birds. Oxford: Blackwell publishing; 2007.

14. McGuigan CC, McIntyre PG, Templeton K. Psittacosis outbreak in Tayside, Scotland, December 2011 to February 2012. Euro Surveill. 2012;17(22):pii=20186. Available from: http://www. eurosurveillance.org/ViewArticle.aspx?Articleld=20186

15. Stewardson AJ, Grayson ML. Psittacosis. Infect Dis Clin North Am. 2010;24(1):7-25.

http://dx.doi.org/10.1016/j.idc.2009.10.003

PMid:20171542

16. Yung AP, Grayson ML. Psittacosis--a review of 135 cases. Med J Aust. 1988;148(5):228-33.

17. Heddema ER, Beld MG, de Wever B, Langerak AA, Pannekoek Y, Duim B. Development of an internally controlled real-time PCR assay for detection of Chlamydophila psittaci in the LightCycler 2.0 system. Clin Microbiol Infect. 2006;12(6):571-5. http://dx.doi.org/10.1111/j.1469-0691.2006.01417.x PMid:16700707

18. Ehricht R, Slickers P, Goellner S, Hotzel H, Sachse K. Optimized DNA microarray assay allows detection and genotyping of single PCR-amplifiable target copies. Mol Cell Probes. 2006;20(1):60-3.

http://dx.doi.org/10.1016/j.mcp.2005.09.003 PMid:16330186

19. ProMED-mail. Psittacosis - Sweden: (Skane, Kronoberg) RFI. Archive Number 20130322.1599238. 22 Mar 2013. Available from: http://www.promedmail.org/

20. ProMED-mail. Psittacosis - Russia: (Saint Petersburg). Archive Number 20130405.1622310. 5 Apr 2013. Available from: http:// www.promedmail.org/

21. Statens Veterinärmedisinska Anstalt (SVA). Papegojsjuka i södra Sverige. [Parrot fever in southern Sweden]. Uppsala: SVA. Updated 21 Mar 2013. [Accessed 23 Apr 2013]. Swedish. Available from: http://www.sva.se/sv/ Djurhalsa1/Zoonoser/Psittakos-papegojsjuka-som-zoonos/ Papegojsjuka-i-sodra-Sverige/

22. Sveriges Ornitologiska Förening (SOF). Vinterfåglar inpå knuten. [Winter birds around your house]. Lilla Brunneby: SOF. [Acccessed 25 Apr 2013]. Swedish. Available from: http://www. turgor.se/net_sofnet_vinter_oldasp/uuser/Valj_lan_AllaArt_ ej_kommun.aspx

23. Swedish Meteorological and Hydrological Institute (SMHI). Februari dominerades av kraftiga temperatursvängningar. [February was dominated by strong fluctuations in temperature]. Norrköping: SMHI. Updated 1 Mar 2013. [Accessed 22 Apr 2013]. Swedish. Available from: http:// www.smhi.se/nyhetsarkiv/februari-dominerades-av-kraftigatemperatursvangningar -1.29014 ? search=yes \& month=3\&ye $\operatorname{ar}=\mathbf{2 0 1 3}$

24. Swedish Meteorological and Hydrological Institute (SMHI). Vårvärmen har låtit vänta på sig i mars. [The arrival of the spring is late]. Norrköping: SMHI. Updated 28 Mar 2013. [Accessed 22 Apr 2013]. Swedish. Available from: http://www.smhi.se/nyhetsarkiv/varvarmen-har-latitvanta-pa-sig-i-mars-1.29626? search=yes\&month=3\&ye $\operatorname{ar}=2013$

25. Swedish Meteorological and Hydrological Institute (SMHI) Vintern 2012/2013 - ganska normal svensk vinter. Norrköping: SMHI. Updated 4 Mar 2013. [Accessed 6 May 2013]. Swedish. Available from: http://www.smhi.se/nyhetsarkiv/vintern-20122013-ganska-normal-svensk-vinter-1.29088?search=yes\&mont $\mathrm{h}=3$ \&year $=2013$ 
26. Pannekoek Y, Dickx V, Beeckman DS, Jolley KA, Keijzers WC, Vretou E, et al. Multi locus sequence typing of Chlamydia reveals an association between Chlamydia psittaci genotypes and host species. PloS One. 2010;5(12):e14179.

27. Harkinezhad T, Geens T, Vanrompay D. Chlamydophila psittaci infections in birds: a review with emphasis on zoonotic consequences. Vet Microbiol. 2009;135(1-2):68-77.

28. Herrmann B, Persson H, Jensen JK, Joensen HD, Klint M, Olsen B. Chlamydophila psittaci in Fulmars, the Faroe Islands. Emerg Infect Dis. 2006;12(2):330-2.

http://dx.doi.org/10.3201/eid1202.050404

PMid:16494766 PMCid:3373105

29. Gaede W, Reckling KF, Dresenkamp B, Kenklies S, Schubert E, Noack U, et al. Chlamydophila psittaci infections in humans during an outbreak of psittacosis from poultry in Germany. Zoonoses Public Health. 2008;55(4):184-8. http://dx.doi.org/10.1111/j.1863-2378.2008.01108.x PMid:18387139

30. Miyairi I, Laxton JD, Wang X, Obert CA, Arva Tatireddigari VR, van Rooijen $\mathrm{N}$, et al. Chlamydia psittaci genetic variants differ in virulence by modulation of host immunity. J Infect Dis. 2011;204(4):654-63.

http://dx.doi.org/10.1093/infdis/jir333

PMid:21791668 PMCid:3203387

31. Thibodeau KP, Viera AJ. Atypical pathogens and challenges in community-acquired pneumonia. Am Fam Physician. 2004;69(7):1699-706.

32. Smittskyddsinstitutet (SMI). Influensarapport, vecka $17(22 / 4-28 / 4), 2013$. [Influenza report week 17 (22/4-28/4) 2013]. Solna: SMI. Updated 6 May 2013. Accessed 7 May 2013]. Swedish. Available from: http://www.smittskyddsinstitutet.se/publikationer/ veckorapporter/influensarapporter/sasongen-20122013/ influensarapport-vecka-17-224---284-2013/

33. Tsiodras S, Kelesidis T, Kelesidis I, Bauchinger U, Falagas ME. Human infections associated with wild birds. J Infect. 2008;56(2):83-98.

http://dx.doi.org/10.1016/j.jinf.2007.11.001

PMid:18096237

34. Smittskyddsinstitutet (SMI). Papegojsjuka i södra Sverige 2013. [Parrot fever in southern Sweden]. Solna: SMI. Updated 18 Mar 2013. [Accessed 7 May 2013]. Swedish. Available from: http://www.smittskyddsinstitutet.se/nyhetsarkiv/2013/ papegojsjuka-i-sodra-sverige 
